\title{
Simultaneous surface modification and mechanical enhancement of micro/nanofiber fabrics achieved by Janus particles
}

\author{
X. Yan ${ }^{1 *}$, A. Cayla ${ }^{1}$, E. Devaux ${ }^{1}$, B. Otazaghine ${ }^{2}, F$. Salaün $^{1}$ \\ ${ }^{1}$ ENSAIT, GEMTEX - Laboratoire de Génie et Matériaux Textiles, F-59000 Lille, France \\ ${ }^{2}$ Polymers Composites and Hybrides (PCH), IMT Mines Alès, Alès, France
}

Received 8 November 2020; accepted in revised form 10 January 2021

\begin{abstract}
The immiscible polymeric blend of polypropylene (PP) and polyvinyl alcohol (PVA) was manufactured into multifilament fibers via the melt-spinning process, of which the mass ratio of PP to PVA was selected as $30 \% / 70 \%$. The PP micro/nanofibers were accessible with the removal of PVA in hot water. Kaolinite particles were also incorporated to modify the micro/nanofibers surface, for functionalization efficiencies play a useful role with the aid of a high specific surface area. The octahedral layers of kaolinite particles were grafted with a regioselective process by octadecyl $\left(\mathrm{C}_{18} \mathrm{H}_{37^{-}}\right)$groups modified into Janus particles to better localize the fillers at the biphasic interface. As a result, the kaolinite particles having a Janus morphology are more distributed at the interface of the polymers, as observed by SEM. The knitting structures are capable of being maintained after the selective phase extraction leaving numbers of micro/nanofibers. After the incorporation of kaolinite particles, there are still some amounts of particles appearing on the surface of PP micro/nanofibers. Besides, there is a mechanical enhancement of the knitted fabrics, especially when the Janus particles are used, even after the selective phase extraction, which the conventional chemical treatment cannot bring. This study sets an example of fabricating PP micro/nanofiber fabrics surface-modified and mechanically enhanced using Janus kaolinite particles.
\end{abstract}

Keywords: polymer composites, micro/nanofiber, polypropylene (PP), melt-spinning, Janus particles

\section{Introduction}

In the textile field, micro/nanofibers are being more and more widely utilized due to their high specific area for reinforcement, biomedical, filtration, and purification uses [1]. There are several strategies for manufacturing micro/nanofibers in the non-woven field, e.g., melt blowing [2, 3], forcespinning [4], and electrospinning [5]. Besides these methods, melt spinning combined with biphasic blending technology is also feasible for producing micro/nanofibers. There are two kinds of fibers with different implementation methods: segmented-pie or islands-in-the-sea bicomponent fibers [6], and the other is physically meltblended biphasic fibers. The former bicomponent fibers are manufactured by an especial bicomponent melt-spinning device with a specific spinneret, and this process gives the possibility of fabricating micro/nanofibers by subjecting them to mechanical or solvent actions [7,8]. The production of latter melt-blended biphasic fibers is conducted via the normal melt-spinning device of a relatively lower cost than the bicomponent melt-spinning one. In this case, due to the shear and extension flows, the dispersed phase is transformed into a fibrillar structure during the melt-spinning process in the form of short micro/nanofibers.

Fakirov $[9,10]$ have conducted systematic researches of physically melt-blended biphasic fibers, and 
one of the core ideas is to manufacture the micro/ nanofibers through the removal of the matrix phase with a solvent. The selective phase extraction is also feasible to be placed after the production of the knitted fabrics from the multifilament yarns. Wang and Sun [11] adopted PP as a dispersed phase for the manufacture of polypropylene micro/nanofibers by melt extrusion, drawing, and selective phase extraction. Their study focused on the changes in the morphology of minor phases. It was found that the design could produce the micro/nanofibers with a number averaged diameter of $2.5 \mu \mathrm{m}$ (minimum/ maximum diameter: $0.4-6.5 \mu \mathrm{m}$ ). The corresponding matrix phase was cellulose acetate butyrate (CAB), of which the related solvent was organic solvent acetone instead of water. However, due to the improvement of people's environmental awareness, the importance of water-soluble polymers has been highlighted. Thermoplastic PVA is an outstanding candidate with an excellent fiber-forming property adopted in the textile industry. Robeson et al. [12] initially used polymer-PVA blends to fabricate micro/nanofibers. The approach is to blend PVA and the other polymer candidate by melt compounding and post orientation. Micro/nanofibers with the diameter of $0.1-5 \mu \mathrm{m}$ were produced, including PP, polystyrene (PS), polyethylene (PE), poly(vinylidene fluoride) (PVDF), cellulose propionate, as well as an elastomer from poly (butylene terephthalate)polytetrahydrofuran block copolymer (Hytrel 4056, DuPont). Recycled polymer scrap was also successfully utilized to fabricate micro/nanofibers, while PVA as sacrificial polymer was proved to be also partially recyclable. Among the polymers, PP is a nonpolar thermoplastic polymer, vastly used in the textile industry, with low cost, density, and thermal conductivity, excellent chemical resistance, thermal stability, elasticity, and toughness. However, PP has some limits, e.g., sensitivity to fire, ultraviolet (UV) radiation, oxygen, and poor dyeability. The incorporation of nanoparticles near the PP surface has a potential to improve the related resistance and functionality.

The clay particles are a branch of industrialized particles from natural materials with low cost, excellent thermal stability, and good dispersion properties [13]. Clay particles possess a layered structure of tetrahedral silica oxide and octahedral $\mathrm{Al}, \mathrm{Mg}$, or Fe oxide. Clay minerals are generally classified into two categories, 1:1 and 2:1, which represent the ratio of the tetrahedral sheet to the octahedral one. Kaolin clays are 1:1 phyllosilicates and montmorillonite (e.g., kaolinite, dickite, nacrite, and halloysite). Kaolinite is very abundant and used mainly in classical applications (paper, ceramics, absorbents for pollution control) $[14,15]$. It is discovered as anisometric platelets with aspect ratios of around 20:1-40:1 [16] with the formula of $\mathrm{Al}_{2} \mathrm{O}_{3} \cdot 2 \mathrm{SiO}_{2} \cdot 2 \mathrm{H}_{2} \mathrm{O}$. It is composed of a silica-containing tetrahedral sheet (TS) combined with an alumina-containing octahedral sheet (OS) [17]. The mineral particles have an inherent Janus character with different basal planes, which can be selectively modified (TS or OS) with hairy polymers. It is potential to enhance the compatibility with different phases [18]. Not all the clay derivatives have inherent Janus properties, and for example, laponite and montmorillonite are symmetrical as 2:1-layered silicates without Janus properties [19]. Weiss et al. [19] tailored kaolinite via polymer chains to fabricate hybrid particles with Janus properties. The regioselective modifications were achieved for one side by simple cation exchange at the silica surfaces (TS layers). Meanwhile, the modifications were also for the other side by covalent grafting with catechol groups at the alumina surfaces (OS layers). The Janus kaolinite particles grafted with PS and PMMA were initially adopted for compatibilization of PSPMMA blend via a solvent casting process. Daitx et al. [18] used a similar methodology to synthesize Janus particles to further investigate their effects on the properties of the blends, e.g., thermal properties. Based on our previous research, it has been found that the regioselective grafting with phosphonic acid groups at the alumina surfaces is also a feasible method to endow the kaolinite with a significantly enhanced Janus morphology. We have found that the modification at single sides, which are alumina surfaces (OS layers), provides a facile method to fabricate Janus particles. The prepared particles realized the interfacial localization of the biphasic polymers PP-PVA [20]. As for melt spinning of biphasic polymeric fibers, we have originally made efforts to thermodynamically control the localization of fillers towards the interface [21]. Therefore, porous PP filaments decorated with fillers were successfully produced after selective phase extraction, where PVA was the dispersed phase. The related schematic figure is illustrated in Figure 1. If PVA becomes the matrix phase, it may provide a novel strategy to produce surface-modified micro/nanofibers. By this method, 


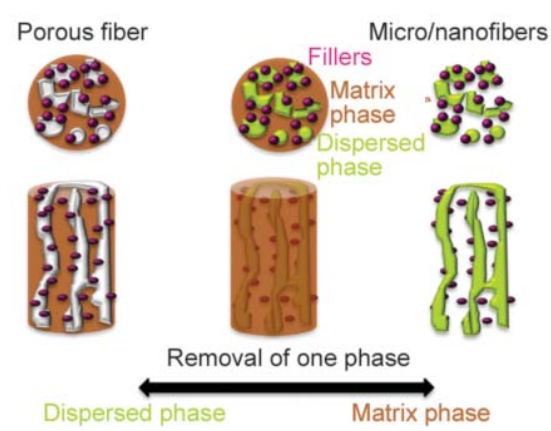

Figure 1. Schematic figure of fabrication of surface-modified porous fibers and micro/nanofibers.

the surface of PP microfibers is easier to be exposed to the outside, which is beneficial for playing surface function. So far, there are no reports on the preparation of micro/nanofiber using the idea of thermodynamic control of fillers.

Therefore, we aim to prepare surface-modified micro/ nanofibers with fillers as the basis for the development of novel functional fibers. In this study, we select PP as the minor phase (PP-PVA ratio: 30/70, wt/wt) to manufacture PP micro/nanofibers filled with nanoparticles and to control the fillers' migration towards the PP-PVA interface [22]. Due to their anisotropic surface, the Janus particles more easily adsorb at the biphasic interface. Herein, the kaolinite particles before and after regioselective modification were used in the melt spinning of PP-PVA biphasic polymer in order to fabricate the PP micro/nanofibers with surface functionality. Observations, including transmission electron microscopy (TEM) and scanning electron microscope (SEM) were applied to determine the morphology and dimension of the fibers. Also, mechanical tests were focused on monofilament fibers and knitted fabrics, before and also after selective phase extraction. Thermal behaviors of the obtained fibers were evaluated via thermogravimetric analysis (TGA) and differential scanning calorimetry (DSC), to analyze the influence of kaolinite particles on the thermal stability and thermal properties of melting. These thermal analyses were done to determine the retention of particles on PP micro/nanofibers and the effect on their aggregate structure.

\section{Experimental section}

\subsection{Materials}

Polypropylene (PP) (PPH 9069) was purchased from Total S.A. Company (Courbevoie, France, spinning grade). Its melting temperature is $168^{\circ} \mathrm{C}$, and the melt flow index is $15 \mathrm{~g} / 10 \min \left(200^{\circ} \mathrm{C}, 2.16 \mathrm{~kg}\right)$. Poly(vinyl alcohol) (PVA) (OKS-8042P), with a melting temperature of about $178^{\circ} \mathrm{C}$, and a melt flow index of about $23 \mathrm{~g} / 10 \mathrm{~min}\left(200^{\circ} \mathrm{C}, 2.16 \mathrm{~kg}\right)$, was supplied by Nichigo Gohsei (Osaka, Japan, spinning grade) [20].

Octadecylphosphonic acid (ODPA) was supplied by Specific Polymers (Montpellier, France). In addition, ethanol and acetone were obtained by Fisher Chemical Company. The kaolinite (PARALUX ${ }^{\mathrm{TM}}$ ) was supplied by the Imerys Company (Paris, France), denoted as KL. Its specific surface area (measured by BET) is $12.2 \pm 1.5 \mathrm{~m}^{2} / \mathrm{g}$, with the aspect ratio $(\alpha)$ of 10 and the average primary particle size $\left(d_{\mathrm{el}}\right)$ of $0.8 \mu \mathrm{m}$. The particles were also surface-modified to generate the Janus particles according to the work of Yah et al. [23] Briefly, $100 \mathrm{~g}$ of KL, $2.5 \mathrm{~g}$ of ODPA, and $300 \mathrm{ml}$ of an ethanol/water solution (96/4) were poured in a $500 \mathrm{ml}$ flask adapted with a condenser. The mixture was stirred under solvent reflux for $15 \mathrm{~h}$, before being centrifuged to get rid of the liquid phase and washed three times with acetone. The modified clay particles were dried under vacuum for subsequent use and denoted as KJ.

\subsection{Sample preparation}

\subsubsection{Melt extrusion of the polymers}

The raw materials of polymers were dried to remove moisture in the oven at $80^{\circ} \mathrm{C}$ for at least $12 \mathrm{~h}$. All of the materials were melt-compounded by using a corotating intermeshing twin-screw extruder (Thermo Haake, screw diameter of $16 \mathrm{~mm}, L / D=25$ ) [24]. The temperature profiles of the five heating zones were adjusted to $160^{\circ} \mathrm{C} / 170^{\circ} \mathrm{C} / 180^{\circ} \mathrm{C} / 190^{\circ} \mathrm{C} / 200^{\circ} \mathrm{C}$, respectively. The screw rotational speed was set as $100 \mathrm{rpm}$, and the extruded rod out of the die was conveyed with the aid of the conveyer belt, being cooled with the air stream, and then cut by the granulator. The blends of PP and PVA without fillers were directly compounded. The weight ratio of the two polymers (PP to PVA) was 30/70 (wt/wt), denoted as $\mathrm{PP}_{30^{-}}$ $\mathrm{PVA}_{70}$. As for the compounds with kaolinite particles, the weight fraction of KL and KJ particles was fixed at $2 \mathrm{wt} . \%$. The blends with particles were mixed by two steps. In the first step, kaolinite particles were compounded with PP, and in the second step, the prepared polymer composites were extruded again with PVA. The samples containing KL and $\mathrm{KJ}$ were denoted as $\mathrm{PP}_{30}-\mathrm{PVA}_{70}-\mathrm{KL}_{2}$ and $\mathrm{PP}_{30}-\mathrm{PVA}_{70}-\mathrm{KJ}_{2}$, respectively. 


\subsubsection{Melt spinning of polymer blends}

The extruded blends were melt-spun to manufacture the multifilament yarns. Before melt spinning, the extrudates were dried at $80^{\circ} \mathrm{C}$ overnight to remove moisture. The melt-spinning process was carried out on a Busschaert Engineering Spinboy I (Deerlijk, Belgium). Table 1 summarizes the component fractions, the melt-spinning temperatures, the rotating speed of the volumetric pump, and the theoretical draw ratio $(D R)$. The melt-spinning temperatures include temperatures of five heating zones in the extruder zone and those of the spin-head and spinneret.

The blends were melted through the single screw extruder and passed through the filter, and two parallel dies with 40 circular holes, of which the diameter is $1.2 \mathrm{~mm}$. A volumetric pump (15 rpm, flow rate: $52.5 \mathrm{~cm}^{3} / \mathrm{min}$ ) was equipped to accurately transport the material to manufacture multifilament yarns composed of 80 monofilaments. The as-spun multifilament yarns were cooled down by the airflow and afterward lubricated by a spin finish oil. It was wateroil-surfactant mixtures to increase the cohesion between the filaments and reduce static electricity. The multifilament yarns were stretched due to the speed difference between the feed roll and the draw one. The theoretical stretching draw ratio $(D R)$ was controlled as $D R=V_{2} / V_{1}$, where $V_{1}$ is the speed of feed roll, and $V_{2}$ is the speed of draw roll. The stretched multifilament yarns were collected on the bobbin. Two different draw ratios (2 or 4) were adopted, $100 \mathrm{rpm}$ of the first roll and 200 or $400 \mathrm{rpm}$ of the second roll. The suffix $-\mathrm{DR}_{2}$ and $-\mathrm{DR}_{4}$ are used for the indication of different draw ratios of the meltspun fibers originated from the extrudates. For example, $\mathrm{PP}_{30}-\mathrm{PVA}_{70}-\mathrm{KL}_{2}-\mathrm{DR}_{4}$ refers to the melt-spun fibers with $D R=4$ from $\mathrm{PP}_{30}-\mathrm{PVA}_{70}-\mathrm{KL}_{2}$ extrudates.

\subsubsection{Preparation and selective phase extraction of the knitted fabrics}

The multifilament yarns were further knitted to achieve fabric implementation. In the first step, the multifilament yarns were twisted (25 twists/meter,
$\mathrm{Z}$ direction) via the twisting machine (Twistec, Barcelona, Spain). In the second step, the twisted multifilament yarns were knitted on a flat knitting machine (Dubied, Couvet, Switzerland), of which the gauge value is 7 needles/inch. The selected texture was $1 \times 1$ Rib stitch, where the loop notation refers to related literature [25].

In order to obtain the knitted fabrics composed of PP micro/nanofibers, the selective phase extraction experiment was carried out to remove the PVA phase of the knitted fabrics under magnetic stirring in a hot water bath. The fabrics were immersed in the distilled water with a temperature of $80^{\circ} \mathrm{C}$, and the extraction time is fixed at $5 \mathrm{~h}$. Finally, the obtained samples were rinsed with warm water to clean the multifilament yarn surface, before being dried overnight in the oven at $50{ }^{\circ} \mathrm{C}$ in order to get rid of water. It was found that almost all the PVA is removable during the selective phase extraction experiment based on the weighing method.

The suffix -Ex is adopted for the indication of the materials after the selective phase extraction experiment. For example, $\mathrm{PP}_{30}-\mathrm{PVA}_{70}-\mathrm{KL}_{2}-\mathrm{DR}_{4}$-Ex refers to the micro/nanofibers after extraction from initial $\mathrm{PP}_{30}-\mathrm{PVA}_{70}-\mathrm{KL}_{2}-\mathrm{DR}_{4}$ fibers. The suffix $-\mathrm{Knit}$ is placed after the indication of the PP-PVA blend fibers to denote the corresponding knitted fabrics. For example, $\mathrm{PP}_{30}-\mathrm{PVA}_{70}-\mathrm{KL}_{2}-\mathrm{DR}_{4}-\mathrm{Knit}$ refers to the knitted fabrics from $\mathrm{PP}_{30}-\mathrm{PVA}_{70}-\mathrm{KL}_{2}-\mathrm{DR}_{4}$ fibers. Similarly, the corresponding knitted fabrics after selective phase extraction is $\mathrm{PP}_{30}-\mathrm{PVA}_{70}-\mathrm{KL}_{2}-\mathrm{DR}_{4}-\mathrm{Knit}-\mathrm{Ex}$. All the denotements of samples are summarized in Table 2.

\subsection{Characterization}

\subsubsection{Morphology observation}

Transmission electron microscopy (TEM) observation (Tecnai G2 F20 S-TWIN, FEI Company, USA) was conducted on the cross-section of the extrudates in Analytical \& Testing Center, Sichuan University. The cross-section was exposed via slicing the sample to the thickness of tens of nanometers with the help of liquid nitrogen.

Table 1. The melt-spinning parameters of the blends with kaolinite particles.

\begin{tabular}{|c|c|c|c|c|c|c|c|}
\hline \multirow{2}{*}{ Denotement } & \multicolumn{3}{|c|}{$\begin{array}{c}\text { Mass fraction } \\
{[\%]}\end{array}$} & \multicolumn{2}{|c|}{$\begin{array}{c}\text { Temperature } \\
{\left[{ }^{\circ} \mathbf{C}\right]}\end{array}$} & \multirow{2}{*}{$\begin{array}{l}\text { Pump } \\
\text { [rpm] }\end{array}$} & \multirow{2}{*}{$D R$} \\
\hline & $\mathbf{P P}$ & PVA & $\begin{array}{c}\text { Filler } \\
\text { KJ or KL }\end{array}$ & Extruder & $\begin{array}{l}\text { Spinhead } \\
\text { Spinneret }\end{array}$ & & \\
\hline $\mathrm{PP}_{30}-\mathrm{PVA}_{70}$ & 30.0 & 70.0 & 0 & $175 / 180 / 185 / 190 / 192$ & 187 & 15 & 2 or 4 \\
\hline $\mathrm{PP}_{30}-\mathrm{PVA}_{70}-\mathrm{KL}_{2}$ & \multirow{2}{*}{29.4} & \multirow{2}{*}{68.6} & \multirow{2}{*}{2} & \multirow{2}{*}{$175 / 180 / 185 / 190 / 194$} & \multirow{2}{*}{189} & \multirow{2}{*}{15} & \multirow{2}{*}{2 or 4} \\
\hline $\mathrm{PP}_{30}-\mathrm{PVA}_{70}-\mathrm{KJ}_{2}$ & & & & & & & \\
\hline
\end{tabular}


Table 2. Denotements of the samples.

\begin{tabular}{|c|c|c|c|c|c|}
\hline \multirow{2}{*}{ Extrudates } & \multicolumn{3}{|c|}{ Melt-spun fibers } & \multirow{2}{*}{$\begin{array}{c}\text { Micro/nanofibers with } \\
\text { the removal of PVA }\end{array}$} & \multirow{2}{*}{$\begin{array}{c}\text { Fabrics with the removal } \\
\text { of PVA }\end{array}$} \\
\hline & Denotement & $D R$ & Knitted fabrics & & \\
\hline \multirow{2}{*}{$\mathrm{PP}_{30}-\mathrm{PVA}_{70}$} & $\mathrm{PP}_{30}-\mathrm{PVA}_{70}-\mathrm{DR}_{2}$ & 2 & $\mathrm{PP}_{30}-\mathrm{PVA}_{70}-\mathrm{DR}_{2}-\mathrm{Knit}$ & $\mathrm{PP}_{30}-\mathrm{PVA}_{70}-\mathrm{DR}_{2}-\mathrm{Ex}$ & $\mathrm{PP}_{30}-\mathrm{PVA}_{70}-\mathrm{DR}_{2}-\mathrm{Knit}-\mathrm{Ex}$ \\
\hline & $\mathrm{PP}_{30}-\mathrm{PVA}_{70}-\mathrm{DR}_{4}$ & 4 & $\mathrm{PP}_{30}-\mathrm{PVA}_{70}-\mathrm{DR}_{4}-\mathrm{Knit}$ & $\mathrm{PP}_{30}-\mathrm{PVA}_{70}-\mathrm{DR}_{4}-\mathrm{Ex}$ & $\mathrm{PP}_{30}-\mathrm{PVA}_{70}-\mathrm{DR}_{4}-\mathrm{Knit}-\mathrm{Ex}$ \\
\hline \multirow{2}{*}{$\mathrm{PP}_{30}-\mathrm{PVA}_{70}-\mathrm{KL}_{2}$} & $\mathrm{PP}_{30}-\mathrm{PVA}_{70}-\mathrm{KL}_{2}-\mathrm{DR}_{2}$ & 2 & $\mathrm{PP}_{30}-\mathrm{PVA}_{70}-\mathrm{KL}_{2}-\mathrm{DR}_{2}-\mathrm{Knit}$ & $\mathrm{PP}_{30}-\mathrm{PVA}_{70}-\mathrm{KL}_{2}-\mathrm{DR}_{2}-\mathrm{Ex}$ & $\mathrm{PP}_{30}-\mathrm{PVA}_{70}-\mathrm{KL}_{2}$-DR2-Knit-Ex \\
\hline & $\mathrm{PP}_{30}-\mathrm{PVA}_{70}-\mathrm{KL}_{2}-\mathrm{DR}_{4}$ & 4 & $\mathrm{PP}_{30}-\mathrm{PVA}_{70}-\mathrm{KL}_{2}-\mathrm{DR}_{4}-\mathrm{Knit}$ & $\mathrm{PP}_{30}-\mathrm{PVA}_{70}-\mathrm{KL}_{2}-\mathrm{DR}_{4}-\mathrm{Ex}$ & $\mathrm{PP}_{30}-\mathrm{PVA}_{70}-\mathrm{KL}_{2}-\mathrm{DR}_{4}-\mathrm{Knit}-\mathrm{Ex}$ \\
\hline \multirow{2}{*}{$\mathrm{PP}_{30}-\mathrm{PVA}_{70}-\mathrm{KJ}_{2}$} & $\mathrm{PP}_{30}-\mathrm{PVA}_{70}-\mathrm{KJ}_{2}-\mathrm{DR}_{2}$ & 2 & $\mathrm{PP}_{30}-\mathrm{PVA}_{70}-\mathrm{KJ}_{2}-\mathrm{DR}_{2}-\mathrm{Knnit}$ & $\mathrm{PP}_{30}-\mathrm{PVA}_{70}-\mathrm{KJ}_{2}-\mathrm{DR}_{2}-\mathrm{Ex}$ & $\mathrm{PP}_{30}-\mathrm{PVA}_{70}-\mathrm{KJ}_{2}-\mathrm{DR}_{2}-\mathrm{Knit}-\mathrm{Ex}$ \\
\hline & $\mathrm{PP}_{30}-\mathrm{PVA}_{70}-\mathrm{KJ}_{2}-\mathrm{DR}_{4}$ & 4 & $\mathrm{PP}_{30}-\mathrm{PVA}_{70}-\mathrm{KJ}_{2}-\mathrm{DR}_{4}-\mathrm{Knit}$ & $\mathrm{PP}_{30}-\mathrm{PVA}_{70}-\mathrm{KJ}_{2}-\mathrm{DR}_{4}-\mathrm{Ex}$ & $\mathrm{PP}_{30}-\mathrm{PVA}_{70}-\mathrm{KJ}_{2}-\mathrm{DR}_{4}-\mathrm{Knit}-\mathrm{Ex}$ \\
\hline
\end{tabular}

The images of the knitted fabrics before and after the selective phase extraction experiment were acquired via a digital camera (Huawei P9 EVA-AL00, Shenzhen, China).

The knitted fabrics from the $\mathrm{PP}_{30}-\mathrm{PVA}_{70}-\mathrm{DR}_{4}$ fibers before and after selective phase extraction were metalized and afterward observed by field emission scanning electron microscopy (SEM) on Apreo S (ThermoFisher Scientific, USA) in Sichuan University (Chengdu, China). The accelerating voltages are from 5.0 to $20.0 \mathrm{kV}$. Also, to better observe the morphology of the biphasic fibers $\left(\mathrm{PP}_{30}-\mathrm{PVA}_{70}\right)$ with kaolinite particles before and after selective phase extraction, further characterization was performed on a scanning electron microscope (FEI Quanta 200 ESEM) in PCH laboratory, IMT Mines Alès (France), accompanied with the secondary electron (SE) and back-scattered electron (BSE) mode. The accelerated voltage was $12.5 \mathrm{kV}$. Before the SEM experiment, the samples were coated with a thin carbon layer.

The aforementioned experiments were repeated at least three times.

\subsubsection{Melt flow index (MFI)}

The melt flow index (MFI) measurement was realized on the Melt Flow Tester (Thermo Haake, USA), according to the standard ASTM D1238 [26]. The piston and the tested polymer were pre-heated for 4 and 3 minutes, respectively. The temperature was kept at $190^{\circ} \mathrm{C}$, and the load during the experiment was selected as $2.16 \mathrm{~kg}$. The MFI value was recorded with the unit $[\mathrm{g} / 10 \mathrm{~min}]$.

\subsubsection{Thermal behaviors}

To evaluate the thermal stability of the samples, the thermogravimetric analysis (TGA) was carried out via a TGA/DSC 3+ (Mettler Toledo, Columbus, Ohio, USA) under nitrogen and air atmosphere at a purge rate of $50 \mathrm{ml} / \mathrm{min}$. For each experiment, a sample of approximately $10 \mathrm{mg}$ was used. To remove the physisorbed water, an isothermal step (10 min, $100^{\circ} \mathrm{C}$ ) was conducted before starting the analysis and then the samples were heated to $700^{\circ} \mathrm{C}$ at a heating rate of $10^{\circ} \mathrm{C} / \mathrm{min}$.

The thermal properties of all the fiber samples after the selective phase extraction were observed with differential scanning calorimetry (DSC) with TGA/ DSC $3+$, under constant nitrogen flow ( $50 \mathrm{ml} / \mathrm{min}$ ). Each milligram sample was placed in a hermetically sealed aluminum pan. The scanning procedure involved heating from 20 to $220^{\circ} \mathrm{C}$ at a rate of $10^{\circ} \mathrm{C} / \mathrm{min}$, during which the melting endotherm was recorded. The parameters including melting temperature ( $T_{\text {peak }}$, maximum of the peak), onset, endset, and range of the melting peaks ( $T_{\text {onset }}, T_{\text {endset }}, \Delta T=$ $T_{\text {endset }}-T_{\text {onset }}$ ), and corresponding enthalpies were measured. In addition, Equation (1) was used to calculate the crystallinity degree $\left(X_{\mathrm{C}}\right)$ :

$X_{\mathrm{c}}=\frac{\Delta H_{\mathrm{f}}}{\Delta H_{\mathrm{f}}^{0}} \cdot 100$

where $\Delta H_{\mathrm{f}}$ is the heat of fusion of the tested samples $[\mathrm{J} / \mathrm{g}]$, and $\Delta H_{\mathrm{f}}^{0}$ is the reference value of the heat of fusion for a perfect $100 \%$ crystalline polymer. As for PP material, $\Delta H_{\mathrm{f}}^{0}$ can be fixed as $209 \mathrm{~J} / \mathrm{g}$ [27]. Herein, due to the almost complete extraction of PVA and low addition amount of kaolinite particles, we ideally only consider the impact of PP to make a semiquantitative analysis.

The aforementioned experiments were repeated at least three times.

\subsubsection{Mechanical properties}

To test the mechanical properties of the filaments, tensile tests were carried out on single monofilaments extracted from the 80-monofilament multifilament yarns, on a machine with the model name of Zwick 1456 (Germany), according to the ISO 5079 standard [28]. The load cell of the machine was $10 \mathrm{~N}$, the test length was $20 \mathrm{~mm}$ and the deformation speed 
was $20 \mathrm{~mm} / \mathrm{min}$. Tensile tests were carried out in a standard atmosphere (relative humidity of $65 \pm 5 \%$ with a temperature of $20 \pm 2^{\circ} \mathrm{C}$ ) [29]. Measurements were conducted for 10 different single monofilaments from the same yarn. In order to examine the fineness [dTex] of each single monofilament before extraction prior to tensile tests, a vibroscope machine (Vibroskop, Lenzing Instruments, Germany) was operated based on the NF G 07-306 standard. The fineness is used to calculate Young's modulus in [MPa] and also tenacity in [cN/Tex].

The mechanical properties of the knitted fabrics from $\mathrm{PP}_{70}-\mathrm{PVA}_{30}-\mathrm{DR}_{3}$ before and after selective phase extraction were also tested on an electromechanical universal test system (MTS Criterion Model 43, Eden Prairie, USA) with a load cell of $10 \mathrm{kN}$. The width of the selected fabrics was near $40 \mathrm{~mm}$, and the gauge length of the sample was selected as $60 \mathrm{~mm}$, and the deformation speed was set as $30 \mathrm{~mm} / \mathrm{min}$. In addition, the thicknesses of the knitted fabrics (millimeter level) were tested by a fabric thickness tester (Sodemat, France), based on the standard ASTM D 1777-96 (2007) [30].

\subsubsection{Air permeability}

The air permeability of textile fabrics is evaluated based on the rate of flow of air passing perpendicularly through a given area of fabric by measuring its difference across the fabric test area at a given pressure over a given period. Transverse air permeability was measured with a machine named 'Permeabilimetre à l'air' (Emi Développement, Bréviandes, France) with a pressure applied of $100 \mathrm{~Pa}$ and a test area of $20 \mathrm{~cm}^{2}$, based on ISO 9237:1995 [31]. Air permeability tests were also carried out in a standard atmosphere (relative humidity: $65 \pm 5 \%$; temperature: $20 \pm 2{ }^{\circ} \mathrm{C}$ ).

\section{Results and discussion}

\subsection{Melt-extruded polymer blends (rod)}

PP and PVA with pristine and modified kaolinites were melt-compounded with the twin-screw extruder. Due to the difference of the particles in the surface tension, the localization is expected to differ within the polymer blends. Thus, TEM observation was conducted to observe the localization of kaolinite particles before and after regioselective modification. The related localization is illustrated in Figure 2, where the dark-colored phase represents the PP phase, and the light-colored phase is the PVA phase. As for unmodified KL particles, there is a more pronounced agglomeration with a stacked structure due to stronger hydrogen bonds. KL particles are distributed at the interface and also in the bulk of the PVA phase. The hydrophilicity of KL particles leads to their migration from the PP phase towards the PVA phase during the melt extrusion process. As for the Janus kaolinite particles, the octahedral layer (alumina face) becomes hydrophobic via regioselective grafting of octadecyl groups $\left(\mathrm{C}_{18} \mathrm{H}_{37^{-}}\right)$. As a result, the polarity and dispersibility of the kaolinite particles are tuned. From the TEM images, it is observed that KJ particles are mainly localized at the interface of PP and PVA due to the regioselective modification of the kaolinite particles. Furthermore, the octahedral structure of $\mathrm{KJ}$ particles with a thinner layer is observed in Figure 2c. Generally, the modification of kaolinite particles into Janus morphology is beneficial for interfacial localization.

The obtained extrudates were prepared to be meltspun, and their fluidity during the high-temperature processing strongly influences the melt spinnability. For the melt-spinning machine, the temperature at which the MFI index is between 15 and $30 \mathrm{~g} / 10 \mathrm{~min}$

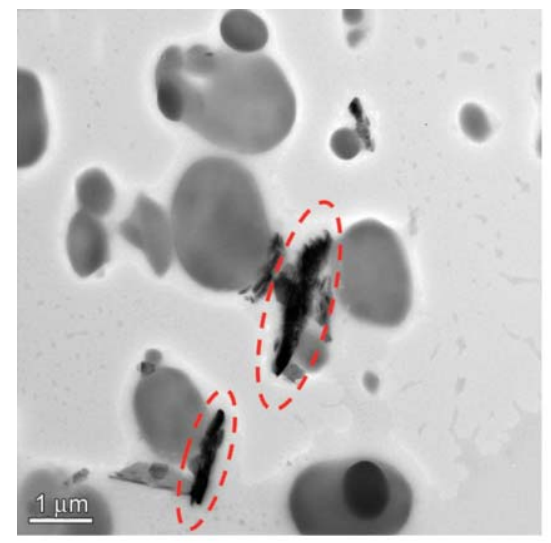

a)

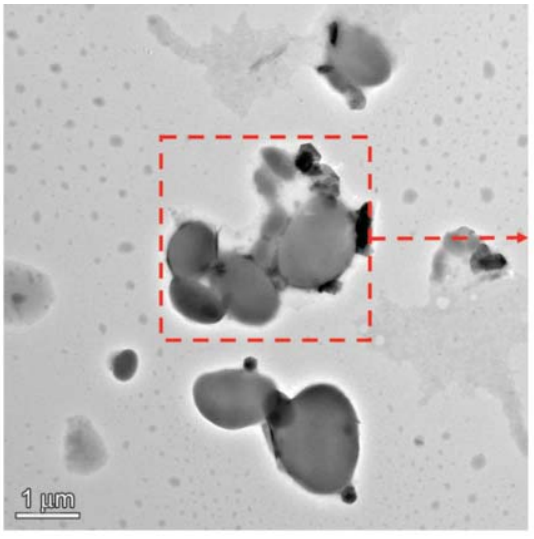

b)

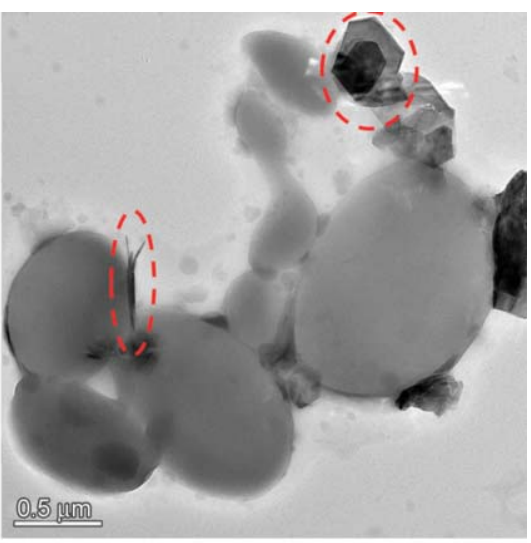

c)

Figure 2. The TEM images of the extrudates in rod form (cross-section) from (a) $\mathrm{PP}_{30}-\mathrm{PVA}_{70}-\mathrm{KL}_{2}$; (b) $\mathrm{PP}_{30}-\mathrm{PVA}_{70}-\mathrm{KJ}_{2}$; (c) zoomed picture of (b). 


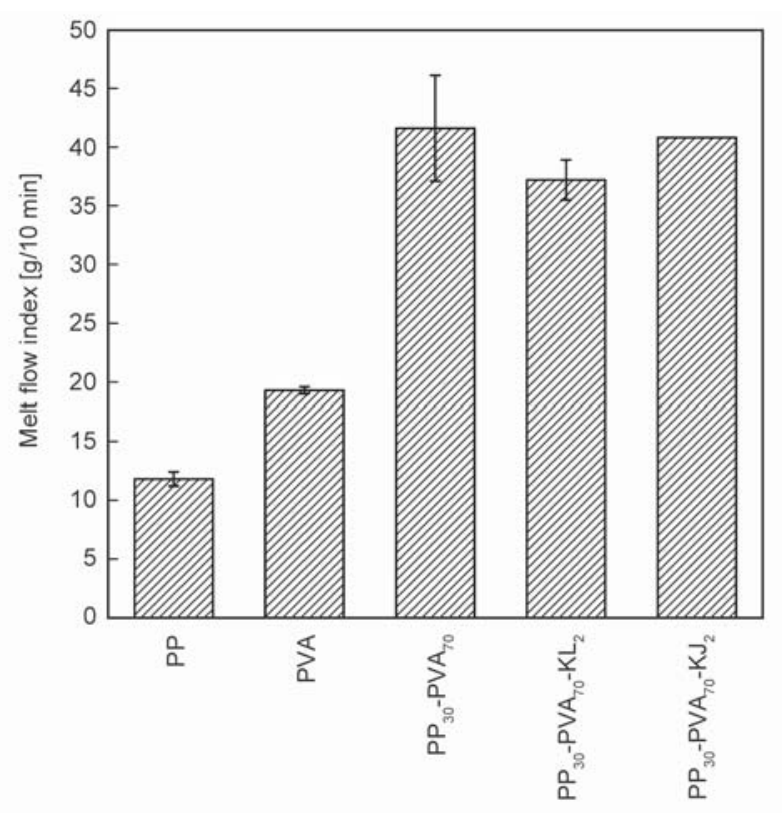

Figure 3. Melt flow index $\left(190^{\circ} \mathrm{C}, 2.16 \mathrm{~kg}\right)$ of PP, PVA, and the blends with/without kaolinite particles.

is a recommended reference, especially for the spinhead and spinneret to succeed in the spinnability. Therefore, the extrudates were characterized by the melt flow indexer. The melt flow indexes of neat polymers PP and PVA and their blends at $190^{\circ} \mathrm{C}$ are presented in Figure 3. The melt flow index of PP is $11.8 \mathrm{~g} / 10 \mathrm{~min}$, while that of PVA is $19.3 \mathrm{~g} / 10 \mathrm{~min}$. After the blending of the polymers, the melt flow index increases up to $41.6 \mathrm{~g} / 10 \mathrm{~min}$. The increment in the fluidity of the blends results from the weak interactions of the two immiscible components PP and PVA [32]. The kaolinite particles slightly decrease the melt flow index. The $\mathrm{PP}_{30}-\mathrm{PVA}_{70}-\mathrm{KL}_{2}$ exhibits the lowest value as $37.2 \mathrm{~g} / 10 \mathrm{~min}$ among the five groups of samples. KL particles are also localized in the PVA matrix phase, which has a more noticeable impact upon the fluidity compared with the KJ particles mostly localized at the biphasic interface. It is originated from the different impacts of particles on the fluidity of the PVA phase and the interaction of the two components.

\subsection{Morphology of the knitted fabrics}

The production of fabrics was realized by twisting, and then the knitting process. Afterward, the knitted fabrics were selectively extracted in the water bath to remove the PVA phase. The PP micro/nanofibers in the PP phase were released after the PVA removal, as the target product of the research. The schematic process of the selective phase extraction of PP micro/nanofiber fabrics is illustrated in Figure 4. The shape of knitted fabrics is maintained, and the color transforms from yellow to white, exhibiting the natural color of PP material. In order to discover the microscopic structures of the obtained samples, SEM observations were realized. It was started from the observation of the samples without particles, shown in Figure 5. Figure 5a and 5d illustrate the morphology of the fabric before selective phase extraction, where the knitting structure Figure 5a and the surface of the biphasic fiber Figure 5d are observable. After the selective phase extraction of PVA in hot water, the physical aspect of the knitting structure is maintained (Figure 5b), with the presence of micro/ nanofibers (Figure 5e, 5c and 5f). The mean diameters are about hundreds of nanometers, corresponding to an increase of the specific surface area. The quantitative calculation of PP micro/nanofiber diameter is difficult to be carried out in the case of the diameter deviations (tens of micrometer in diameter) of the $\mathrm{PP}_{30}-\mathrm{PVA}_{70}-\mathrm{DR}_{4}$ fibers before selective phase extraction. This is common for the melt-spun multifilament yarns from the immiscible polymer blends due to uncontrollable swelling coefficient and inhomogeneous morphology. Furthermore, it is distinguished in Figure $5 f$ that the micro/nanofibers are not entirely isolated. Instead, the micro/nanofibers are interconnected, which is also the reason for the

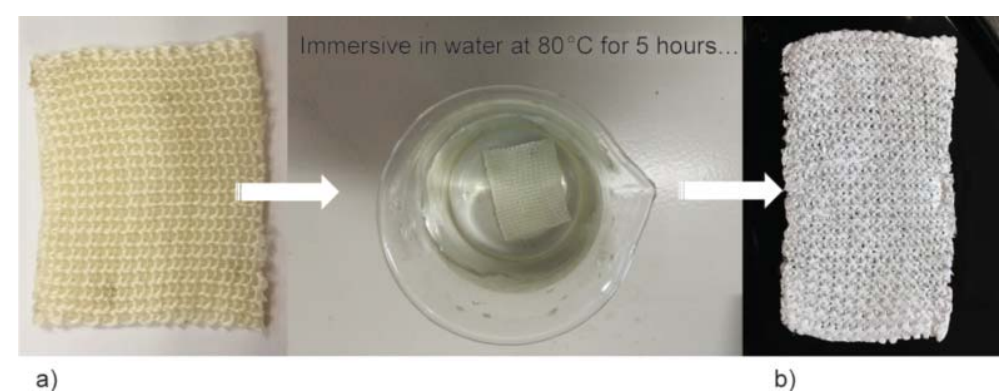

Figure 4. The selective phase extraction process of $\mathrm{PP}_{30}-\mathrm{PVA}_{70}-\mathrm{DR}_{4}$ fabrics. (a) The fabric before extraction; (b) the fabric after extraction. 


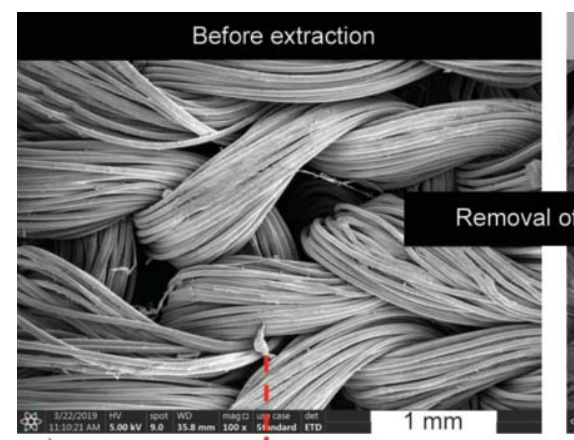

a)

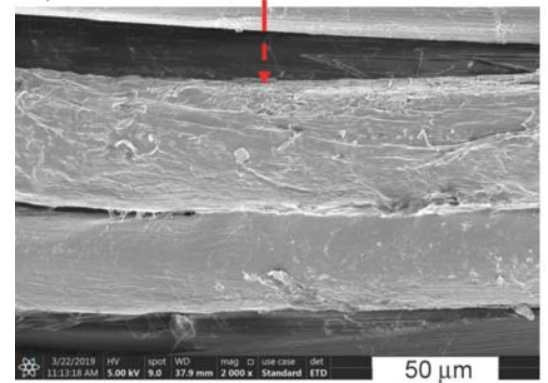

d)
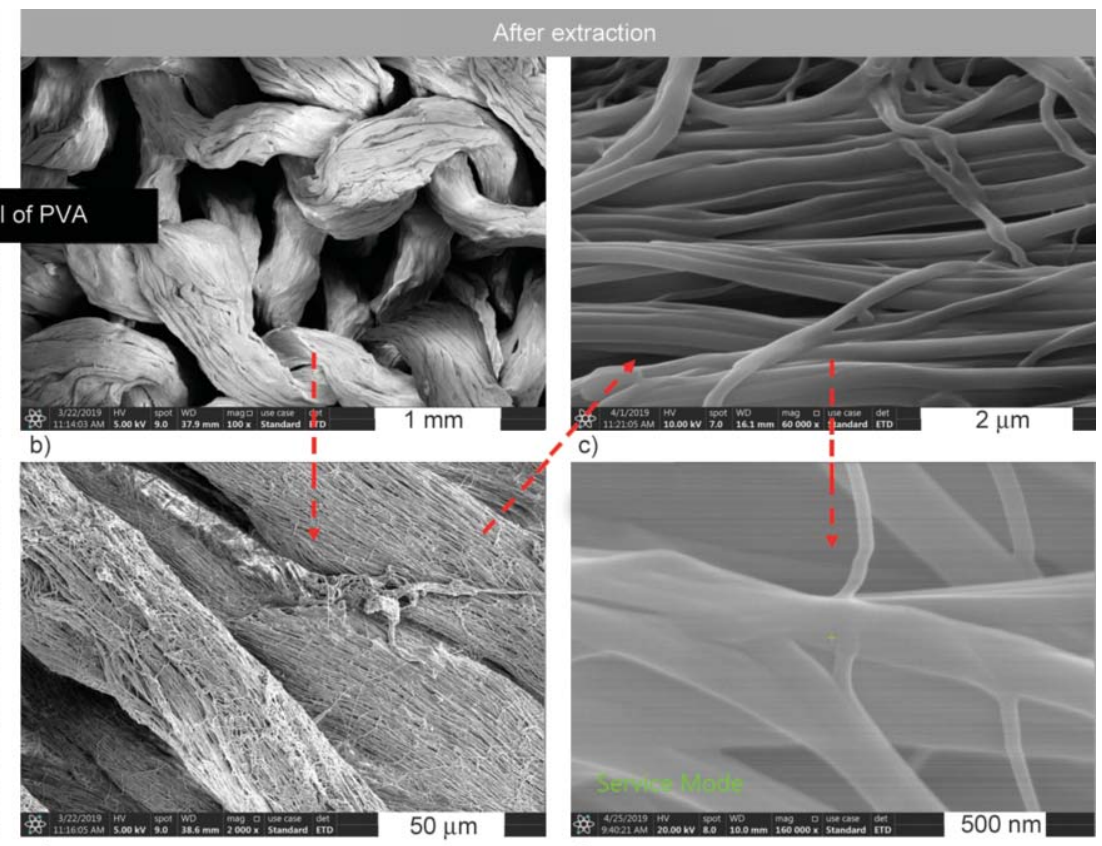

e) f)

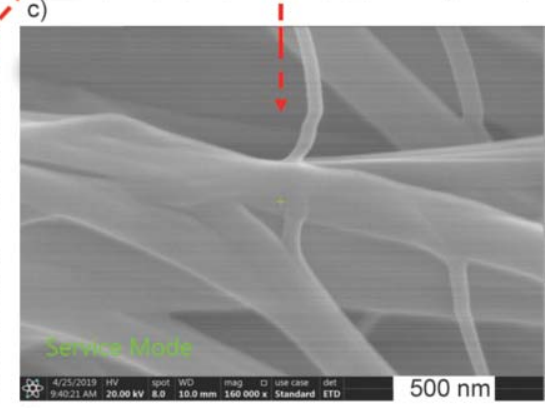

Figure 5. SEM images of knitted $\mathrm{PP}_{30}-\mathrm{PVA}_{70}-\mathrm{DR}_{4}$ fabrics with increasing magnification. (a), (d) before selective phase extraction; (b ), (c), (e), (f) after selective phase extraction.

well maintaining of the monofilament and knitting structure after selective phase extraction.

Furthermore, to investigate the morphology of the fibers filled with kaolinite particles, the related SEM images are displayed in Figure 6. A previous study has explained and successfully demonstrated the

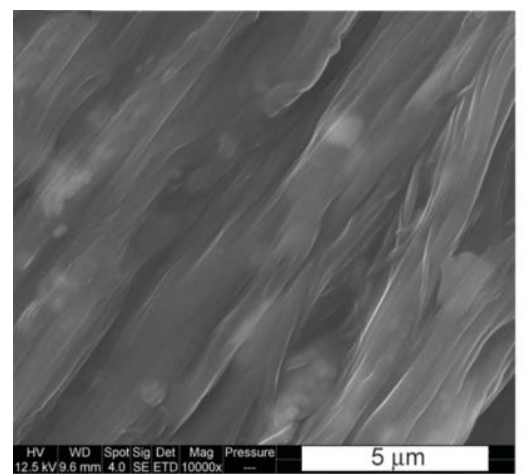

$$
\text { a) }
$$

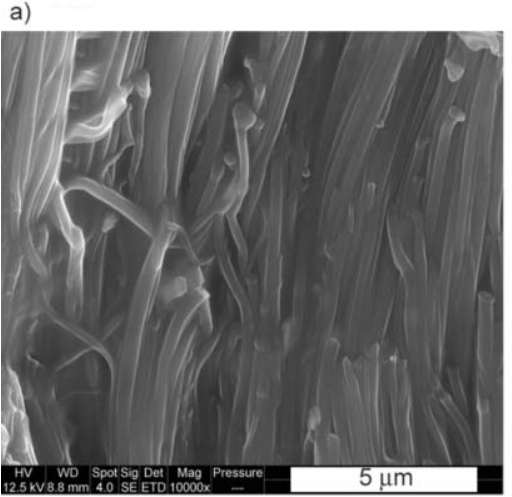

c) method of detecting the particle localization by BSE mode [20]. The white dots are the kaolinite particles on the BSE images. The surface of the fibers is rough, and the fibrillar structure is visible, even before the selective phase extraction, and some particles have migrated towards the surface. In order to

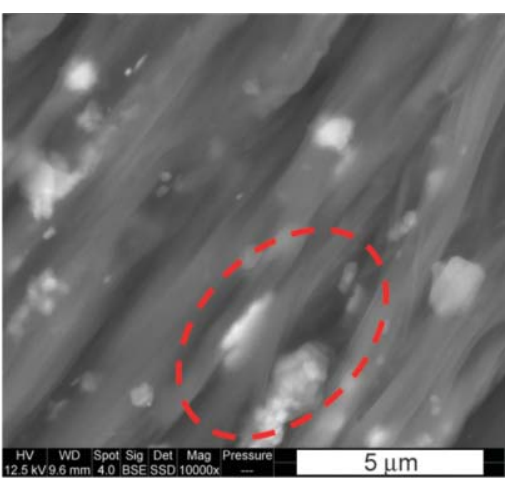

b)

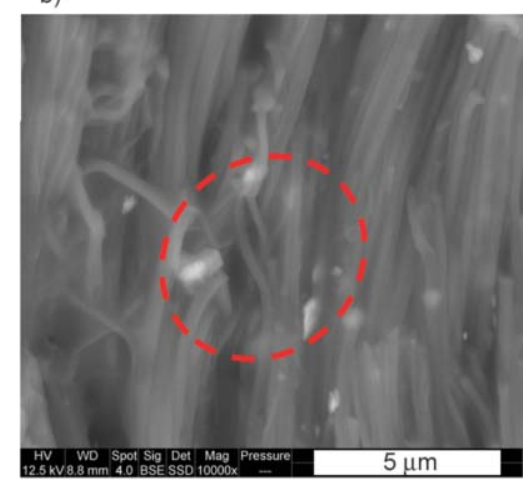

d)

Figure 6. SEM images of (a) $\mathrm{PP}_{30}-\mathrm{PVA}_{70}-\mathrm{KL}_{2}-\mathrm{DR}_{4}$ fibers; (b) $\mathrm{BSE}$ of (a); (c) $\mathrm{PP}_{30}-\mathrm{PVA}_{70}-\mathrm{KJ}_{2}-\mathrm{DR}_{4}$ fibers; (d) $\mathrm{BSE}$ of (c). 


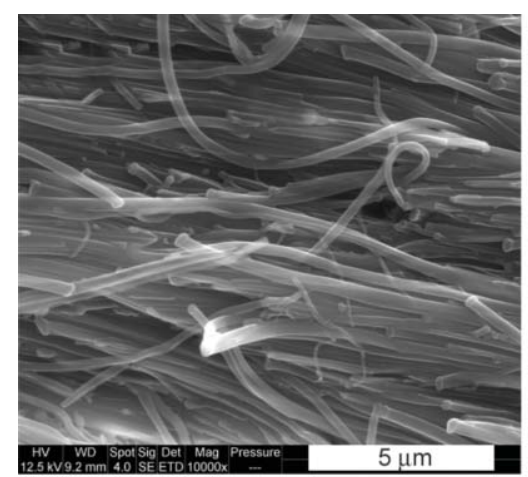

a)

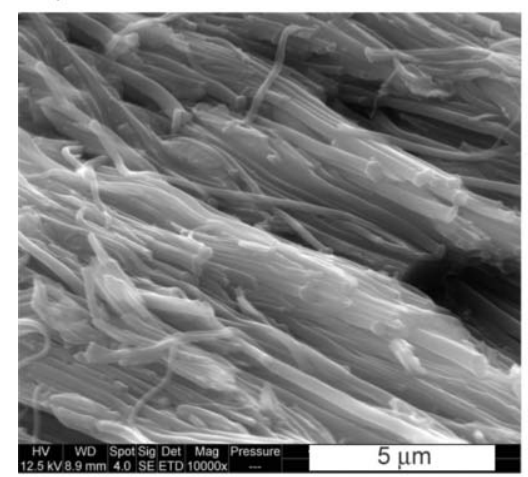

d)

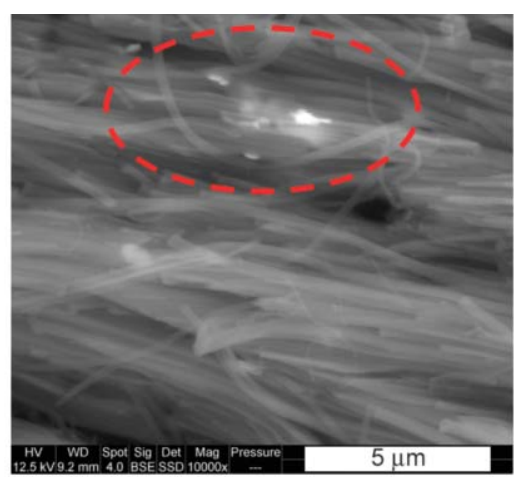

b)

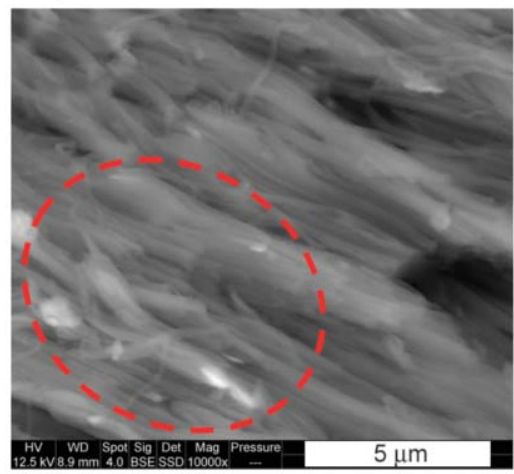

e)

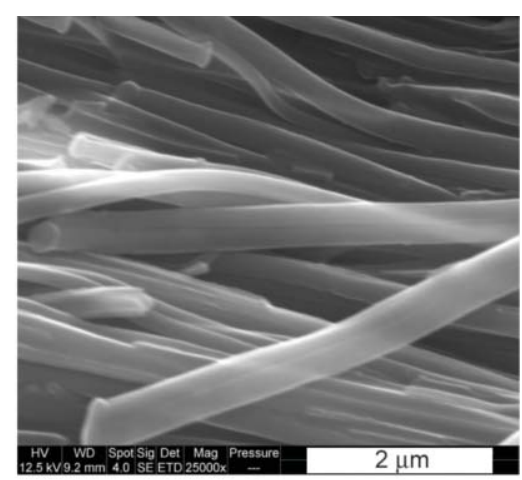

c)

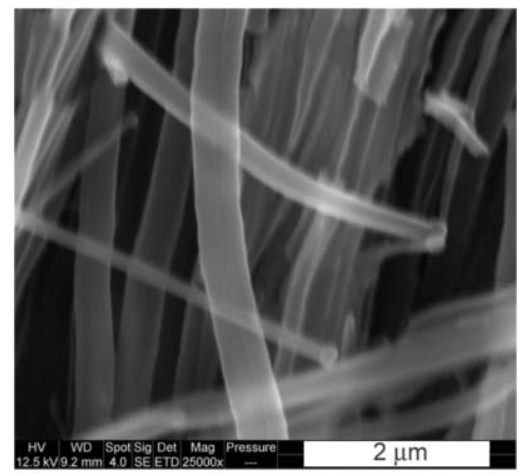

f)

Figure 7. SEM images of (a), (b), (c) $\mathrm{PP}_{30}-\mathrm{PVA}_{70}-\mathrm{KL}_{2}-\mathrm{DR}_{4}$ fibers after extraction; (d), (e), (f) $\mathrm{PP}_{30}-\mathrm{PVA}_{70}-\mathrm{KJ}_{2}-\mathrm{DR}_{4}$ fibers after extraction ((b), (e) BSE mode of (a), (d)).

further reveal the localization of fillers at the biphasic interface, fibers after selective phase extraction were also observed via SEM characterization coupled with BSE mode. The related results are illustrated in Figure 7. Firstly, the morphology of a large number of micro/nanofibers is observable after the selective phase extraction (Figure $7 \mathrm{a}$ and $7 \mathrm{~d}$ ), with the diameter of hundreds of nanometers (Figure 7c and 7f). Secondly, some kaolinite particles are retaining on the PP surface according to the BSE mode observation (Figure $7 \mathrm{~b}$ and $7 \mathrm{e}$ ).

For the pellets and the obtained fibers, we have found that the PVA is completely accessible during the selective phase extraction experiment with hot water by weighing method. In order to investigate if some kaolinite particles retain on the PP micro/nanofibers, an indirect method is also feasible by using the thermogravimetric analysis (TGA). The detailed results are displayed in Figure 8. The TGA analyses of kaolinite particles have been done in the previous study to reveal their thermal stability [20]. Based on the TGA data, the residues at $700^{\circ} \mathrm{C}$ are summarized in Table 3. In the previous study, it has been observed that the initial decomposition temperatures ( $5 \%$ decomposition) of $\mathrm{KL}$ and $\mathrm{KJ}$ particles were around $500{ }^{\circ} \mathrm{C}$ under nitrogen and air atmospheres. In addition, their residues at $700^{\circ} \mathrm{C}$ were approximately about $85-86 \%$, of which the modified kaolinite exhibits a higher weight loss for the degradation of the grafted ODPA. There is no residue for unfilled PP micro/nanofibers at $700^{\circ} \mathrm{C}$, but those for the PP micro/nanofibers filled with kaolinite are over $2.7 \%$ in any circumstances. Thus, it proves that both KL and KJ particles are embedded with the PP micro/ nanofibers and partially exposed to the external environment, from SEM observation and TGA analysis. The retention of particles is mainly ascribed to two reasons. The first is their interfacial localization within the biphasic polymers, especially KJ particles. The second is their large dimension compared with the phase size of polymers. The average primary particle size of kaolinite particles is $800 \mathrm{~nm}$, of the equivalent scale of micro/nanofiber diameters and the spacing between the micro/nanofibers, which is distinguishable from Figure 5 and Figure 7. It indicates that the particles within the PVA phase of the extrudates (referable to Figure 2) have the possibility to be bridged with the PP phase during the melt-spinning process, for the scale of the PVA phase drops sharply and cannot fully accommodate kaolinite particles. 

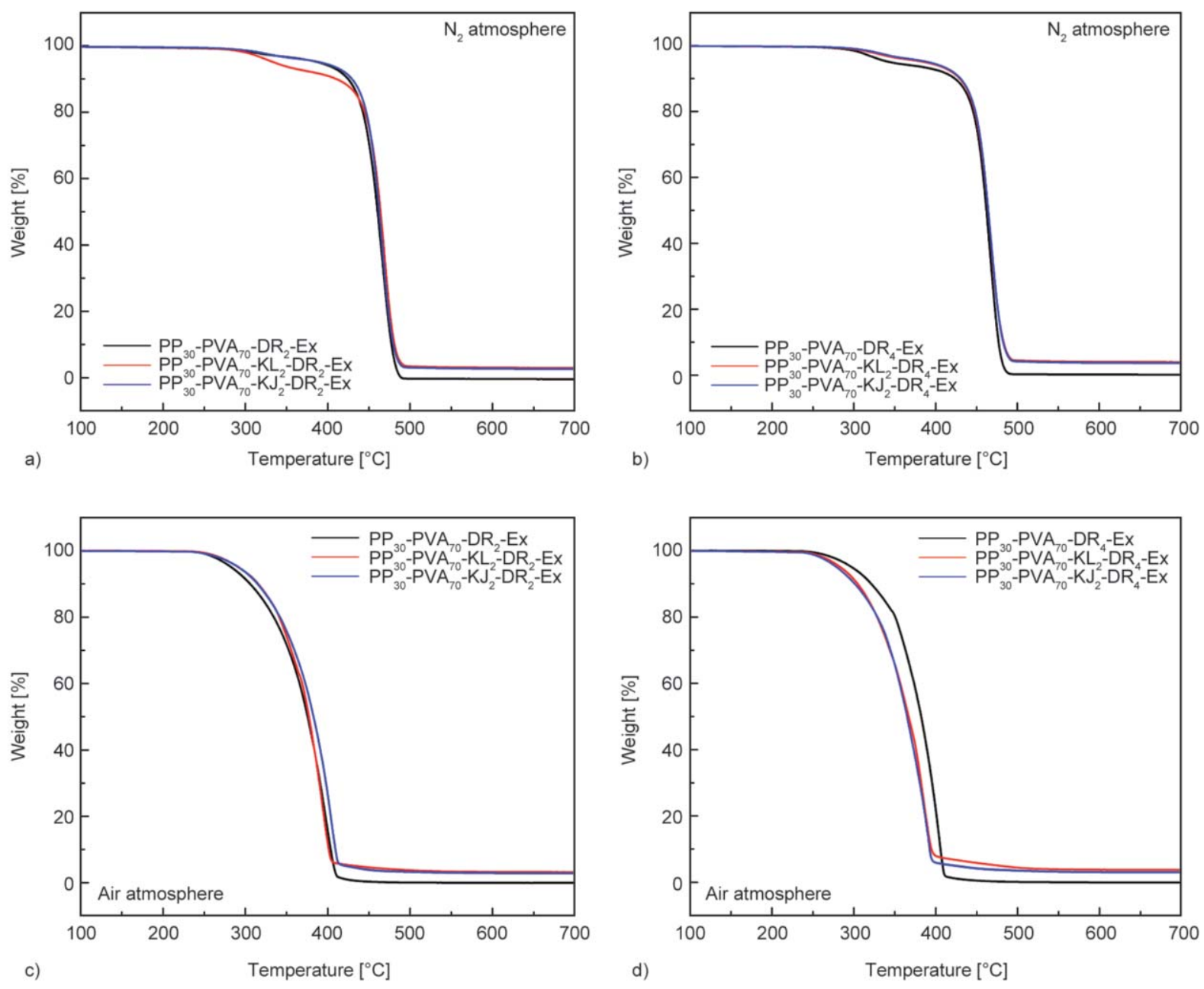

Figure 8. TGA results of the PP micro/nanofibers extracted from $\mathrm{PP}_{30}-\mathrm{PVA}_{70}$ blend fibers with different draw ratios under different atmospheres. (a) $D R=2, \mathrm{~N}_{2}$ atmosphere; (b) $D R=4, \mathrm{~N}_{2}$ atmosphere; (c) $D R=2$, air atmosphere; (d) $D R=4$, air atmosphere.

Table 3. Residues (at $700^{\circ} \mathrm{C}$ ) of kaolinite particles and PP micro/nanofibers extracted from $\mathrm{PP}_{30}-\mathrm{PVA}_{70}$ blend fibers with different draw ratios under different atmospheres.

\begin{tabular}{|l|c|c|}
\hline \multicolumn{1}{|c|}{ Samples } & $\begin{array}{c}\text { Residue in } \mathbf{N}_{\mathbf{2}} \\
\text { atmosphere } \\
{[\%]}\end{array}$ & $\begin{array}{c}\text { Residue in air } \\
\text { atmosphere } \\
{[\%]}\end{array}$ \\
\hline $\mathrm{KL}$ particles & 86.1 & 86.1 \\
\hline $\mathrm{KJ}$ particles & 85.1 & 84.7 \\
\hline $\mathrm{PP}_{30}-\mathrm{PVA}_{70}-\mathrm{DR}_{2}-\mathrm{Ex}$ & 0.0 & 0.0 \\
\hline $\mathrm{PP}_{30}-\mathrm{PVA}_{70}-\mathrm{KL}_{2}-\mathrm{DR}_{2}-\mathrm{Ex}$ & 3.0 & 3.3 \\
\hline $\mathrm{PP}_{30}-\mathrm{PVA}_{70}-\mathrm{KJ}_{2}-\mathrm{DR}_{2}-\mathrm{Ex}$ & 2.7 & 2.9 \\
\hline $\mathrm{PP}_{30}-\mathrm{PVA}_{70}-\mathrm{DR}_{4}-\mathrm{Ex}$ & 0.1 & 0.0 \\
\hline $\mathrm{PP}_{30}-\mathrm{PVA}_{70}-\mathrm{KL}_{2}-\mathrm{DR}_{4}-\mathrm{Ex}$ & 4.0 & 3.8 \\
\hline $\mathrm{PP}_{30}-\mathrm{PVA}_{70}-\mathrm{KJ}_{2}-\mathrm{DR}_{4}-\mathrm{Ex}$ & 3.7 & 3.0 \\
\hline
\end{tabular}

\subsection{Thermal properties}

The crystallization degree is an important and easily measurable parameter to describe the aggregate structure and is inferable from the DSC results for the thermal properties. Therefore, the DSC measurement was carried out towards the obtained PP micro/ nanofibers. The DSC curves are displayed in Figure 9, and related details are summarized in Table 4. There is a single peak for the PP micro/nanofibers when the draw ratio is 2 , with a melting point of $165^{\circ} \mathrm{C}$. In addition, the introduction of the Janus kaolinite allows shifting the melting point to the higher temperatures, but there is no significant modification of the crystallinity degree. When the draw ratio is 4 , the crystallinity degree is increased from 30.4 to $32.1 \%$, and the melting point is also increased from 165 to $168^{\circ} \mathrm{C}$. The incorporation of Janus kaolinite particles gives rise to the further increment of crystallinity degree towards $33.4 \%$. Furthermore, the endothermic curve becomes multi-peak when the draw ratio is enhanced, especially when Janus KJ particles are introduced. It is ascribed to the difference of crystal forms or the degree of their perfection due to 

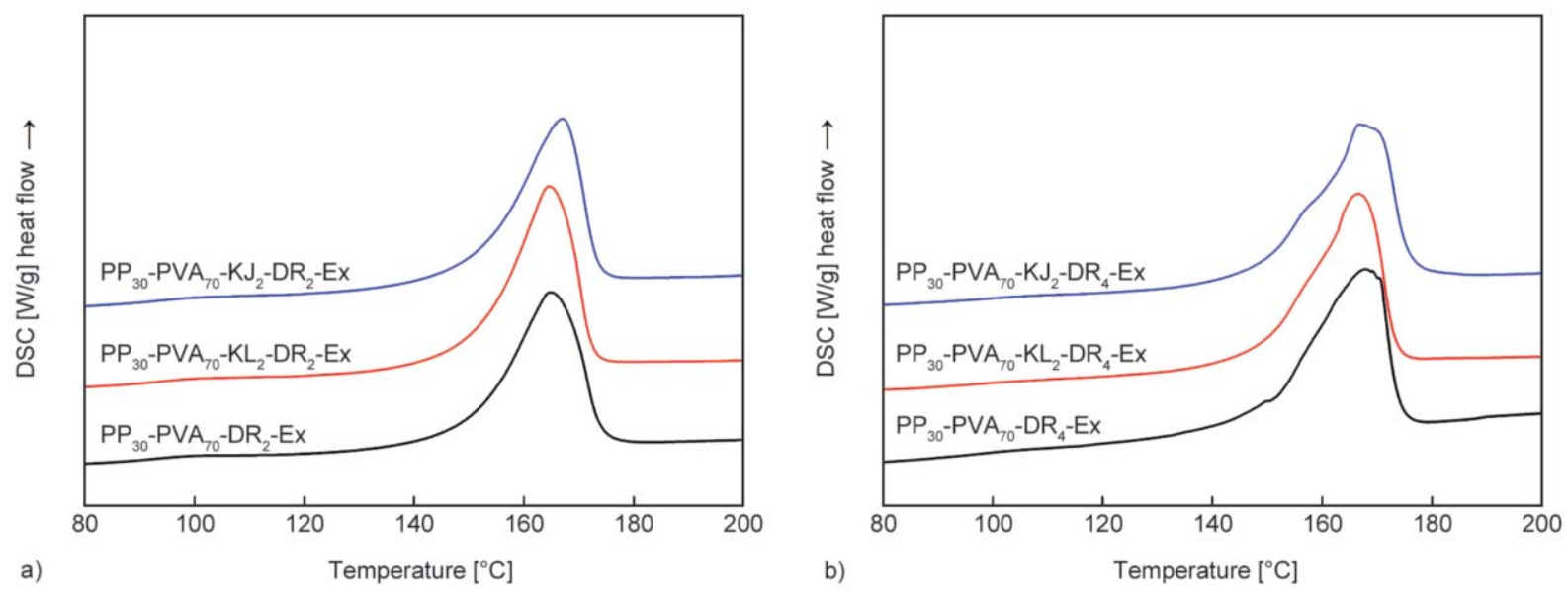

Figure 9. DSC spectra of PP micro/nanofibers after extraction (a) from $\mathrm{PP}_{30}-\mathrm{PVA}_{70}$ with/without kaolinite particles with $D R=2$; (b) from $\mathrm{PP}_{30}-\mathrm{PVA}_{7} 0$ with/without kaolinite particles with $D R=4$.

Table 4. Thermal properties of $\mathrm{PP}$ micro/nanofibers extracted from $\mathrm{PP}_{30}-\mathrm{PVA}_{70}$ with/without kaolinite particles with different draw ratios.

\begin{tabular}{|l|c|c|c|c|c|c|c|}
\hline & Draw ratio & $\begin{array}{c}\text { Enthalpy } \\
{[\mathbf{J} / \mathbf{g}]}\end{array}$ & $\begin{array}{c}\boldsymbol{X}_{\mathbf{c}} \\
{[\mathbf{\%}]}\end{array}$ & $\begin{array}{c}\boldsymbol{T}_{\text {onset }} \\
{\left[{ }^{\circ} \mathbf{C}\right]}\end{array}$ & $\begin{array}{c}\boldsymbol{T}_{\text {endset }} \\
{\left[{ }^{\circ} \mathbf{C}\right]}\end{array}$ & $\begin{array}{c}\Delta \boldsymbol{T} \\
{\left[{ }^{\circ} \mathbf{C}\right]}\end{array}$ & $\begin{array}{c}\boldsymbol{T}_{\text {peak }} \\
{\left[{ }^{\circ} \mathbf{C}\right]}\end{array}$ \\
\hline $\mathrm{PP}_{30}-\mathrm{PVA}_{70}-\mathrm{DR}_{2}-\mathrm{Ex}$ & 2 & 63.48 & 30.4 & 150.6 & 174.0 & 23.4 & 164.8 \\
\hline $\mathrm{PP}_{30}-\mathrm{PVA}_{70}-\mathrm{KL}_{2}-\mathrm{DR}_{2}-\mathrm{Ex}$ & 2 & 67.94 & 32.5 & 151.6 & 172.4 & 20.8 & 164.6 \\
\hline $\mathrm{PP}_{30}-\mathrm{PVA}_{70}-\mathrm{KJ}_{2}-\mathrm{DR}_{2}-\mathrm{Ex}$ & 2 & 62.94 & 30.1 & 151.9 & 173.4 & 21.5 & 167.1 \\
\hline $\mathrm{PP}_{30}-\mathrm{PVA}_{70}-\mathrm{DR}_{4}-\mathrm{Ex}$ & 4 & 67.10 & 32.1 & 150.2 & 173.9 & 23.7 & 167.9 \\
\hline $\mathrm{PP}_{30}-\mathrm{PVA}_{70}-\mathrm{KL}_{2}-\mathrm{DR}_{4}-\mathrm{Ex}$ & 4 & 67.81 & 32.4 & 155.5 & 173.4 & 17.9 & 166.5 \\
\hline $\mathrm{PP}_{30}-\mathrm{PVA}_{70}-\mathrm{KJ}_{2}-\mathrm{DR}_{4}-\mathrm{Ex}$ & 4 & 69.91 & 33.4 & 155.7 & 175.8 & 20.1 & 166.6 \\
\hline
\end{tabular}

different recrystallization situation at high temperatures during drawing [33, 34].

\subsection{Mechanical behaviors}

The incorporation of kaolinite particles inevitably influences the mechanical properties of the multifilament yarns. The tensile tests were realized for the monofilaments randomly extracted from them. The mechanical properties of the $\mathrm{PP}_{30}-\mathrm{PVA}_{70}$ filaments with and without kaolinite particles and the related representative stress-strain curves are illustrated in Table 5 and Figure 10, respectively. A low draw ratio (chosen as 2) during the melt-spinning process is usually not conducive to crystallization and orientation development with good mechanical properties of fibers. The related fibers exhibit low tenacity and high breaking elongation, which is ascribed to the low molecular chain orientation and low crystallization degree. The addition of kaolinite particles into the polymer blend significantly enhances Young's modulus and tenacity, while the breaking elongation is slightly decreased.

With the increment of the draw ratio from 2 to 4 , the mechanical properties are enhanced significantly. Young's modulus is increased sharply from 842 to
$2916 \mathrm{MPa}$, while the tenacity increases from 5.8 to $19.4 \mathrm{cN} /$ Tex. Meanwhile, from the shape of the curves, it is illustrated that the ductility of the fibers is significantly decreased, and breaking elongation is decreased from 47 to $21 \%$. The incorporation of kaolinite particles becomes detrimental to Young's modulus as well as the tenacity. Based on the stressstrain curves, it is observed that within a certain degree of strain, the stress is enhanced due to the kaolinite particles. Meanwhile, the particles as stress concentration points lead to the advance of breakage, especially KJ particles. The diameter of the PP micro/nanofibers is in the same order of magnitude as the diameter of the kaolinite particles. Therefore, the

Table 5. Mechanical properties of the composite fibers from $\mathrm{PP}_{30}-\mathrm{PVA}_{70}$ with/without kaolinite particles.

\begin{tabular}{|l|c|c|c|}
\hline \multicolumn{1}{|c|}{ Fibers } & $\begin{array}{c}\text { Young's } \\
\text { modulus } \\
{[\mathbf{M P a}]}\end{array}$ & $\begin{array}{c}\text { Tenacity } \\
{[\mathbf{c N} / \text { Tex] }}\end{array}$ & $\begin{array}{c}\text { Breaking } \\
\text { elongation } \\
{[\%]}\end{array}$ \\
\hline $\mathrm{PP}_{30}-\mathrm{PVA}_{7}-\mathrm{DR}_{2}$ & $842 \pm 124$ & $5.8 \pm 1.0$ & $47 \pm 14$ \\
\hline $\mathrm{PP}_{30}-\mathrm{PVA}_{7}-\mathrm{KL}_{2}-\mathrm{DR}_{2}$ & $1638 \pm 446$ & $7.0 \pm 1.0$ & $35 \pm 13$ \\
\hline $\mathrm{PP}_{30}-\mathrm{PVA}_{7}-\mathrm{KJ}_{2}-\mathrm{DR}_{2}$ & $1810 \pm 674$ & $7.3 \pm 1.4$ & $34 \pm 9$ \\
\hline $\mathrm{PP}_{30}-\mathrm{PVA}_{7}-\mathrm{DR}_{4}$ & $2916 \pm 431$ & $19.4 \pm 1.9$ & $21 \pm 3$ \\
\hline $\mathrm{PP}_{30}-\mathrm{PVA}_{7}-\mathrm{KL}_{2}-\mathrm{DR}_{4}$ & $1987 \pm 209$ & $18.6 \pm 1.8$ & $17 \pm 2$ \\
\hline $\mathrm{PP}_{30}-\mathrm{PVA}_{7}-\mathrm{KJ}_{2}-\mathrm{DR}_{4}$ & $2165 \pm 225$ & $15.8 \pm 3.7$ & $13 \pm 3$ \\
\hline
\end{tabular}



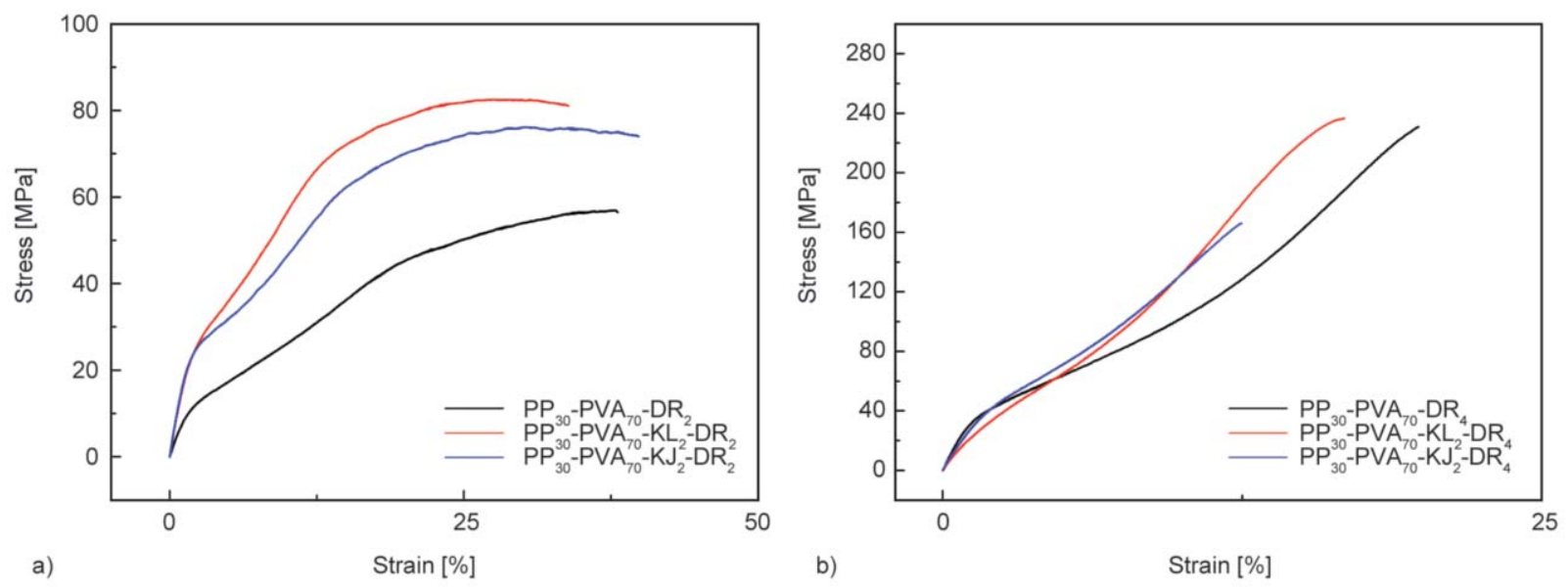

Figure 10. Stress-strain curves of (a) $\mathrm{PP}_{30}-\mathrm{PVA}_{7}-\mathrm{DR}_{2}$ fibers with/without kaolinites; (b) $\mathrm{PP}_{30}-\mathrm{PVA}_{7}-\mathrm{DR}_{4}$ fibers with/without kaolinites.

increase of draw ratio brings about more stress concentration points.

As for the knitted fabrics, the related mechanical behaviors were also investigated via the tensile tests. Through these tests, the effect of the selective phase extraction was also taken into consideration. A higher draw ratio during the melt-spinning process leads to the enhancement of the mechanical properties of the monofilament fibers with a reduced thickness, which is beneficial for the knitting process. Therefore, the knitted fabrics from multifilament yarns with $D R$ of 4 were tested for mechanical properties. The mechanical properties, as well as the air permeability of the knitted fabrics from $\mathrm{PP}_{30}-\mathrm{PVA}_{70}$ fibers before and after selective phase extraction, are illustrated in Table 6. The stress-strain curves of knitted fabrics from $\mathrm{PP}_{30}-\mathrm{PVA}_{70}$ fibers with $D R=4$ are also displayed in Figure 11. As for the fabrics before selective

Table 6. Mechanical properties of the knitted fabrics from $\mathrm{PP}_{30}-\mathrm{PVA}_{70}$ fibers.

\begin{tabular}{|c|c|c|c|c|c|c|}
\hline Fabrics & $\begin{array}{c}\text { Thickness } \\
\text { [mm] }\end{array}$ & $\begin{array}{l}\text { Width } \\
\text { [mm] }\end{array}$ & $\begin{array}{l}\text { Areal density } \\
\qquad\left[\mathrm{g} / \mathrm{m}^{2}\right]\end{array}$ & $\begin{array}{c}\text { Maximum stress } \\
{[\mathrm{MPa}]}\end{array}$ & $\begin{array}{c}\text { Elongation at } \\
\text { maximum force } \\
{[\%]}\end{array}$ & $\begin{array}{c}\text { Air permeability } \\
{[\mathrm{mm} / \mathrm{s}]}\end{array}$ \\
\hline $\mathrm{PP}_{30}-\mathrm{PVA}_{70}-\mathrm{DR}_{4}-\mathrm{Knit}$ & 2.451 & 42 & 838.7 & $8.6 \pm 0.2$ & $86.3 \pm 3.5$ & $2532 \pm 45$ \\
\hline $\mathrm{PP}_{30}-\mathrm{PVA}_{70}-\mathrm{KL}_{2}-\mathrm{DR}_{4}-\mathrm{Knit}_{\text {nit }}$ & 2.359 & 42 & 825.4 & $10.8 \pm 0.8$ & $87.8 \pm 3.9$ & $2780 \pm 109$ \\
\hline $\mathrm{PP}_{30}-\mathrm{PVA}_{70}-\mathrm{KJ}_{2}-\mathrm{DR}_{4}-\mathrm{Knit}$ & 2.353 & 41 & 824.9 & $11.3 \pm 0.1$ & $67.8 \pm 1.5$ & $2780 \pm 109$ \\
\hline $\mathrm{PP}_{30}-\mathrm{PVA}_{70}-\mathrm{DR}_{4}-\mathrm{Knit}-\mathrm{Ex}$ & 1.840 & 41 & 319.3 & $5.8 \pm 0.5$ & $153.9 \pm 14.3$ & $2571 \pm 187$ \\
\hline $\mathrm{PP}_{30}-\mathrm{PVA}_{70}-\mathrm{KL}_{2}-\mathrm{DR}_{4}-\mathrm{Knit}-\mathrm{Ex}$ & 1.715 & 42 & 307.3 & $5.3 \pm 0.1$ & $111.5 \pm 14.0$ & $2634 \pm 98$ \\
\hline $\mathrm{PP}_{30}-\mathrm{PVA}_{70}-\mathrm{KJ}_{2}-\mathrm{DR}_{4}-\mathrm{Knit}-\mathrm{Ex}$ & 1.825 & 42 & 302.0 & $6.8 \pm 0.6$ & $148.2 \pm 21.7$ & $2991 \pm 190$ \\
\hline
\end{tabular}
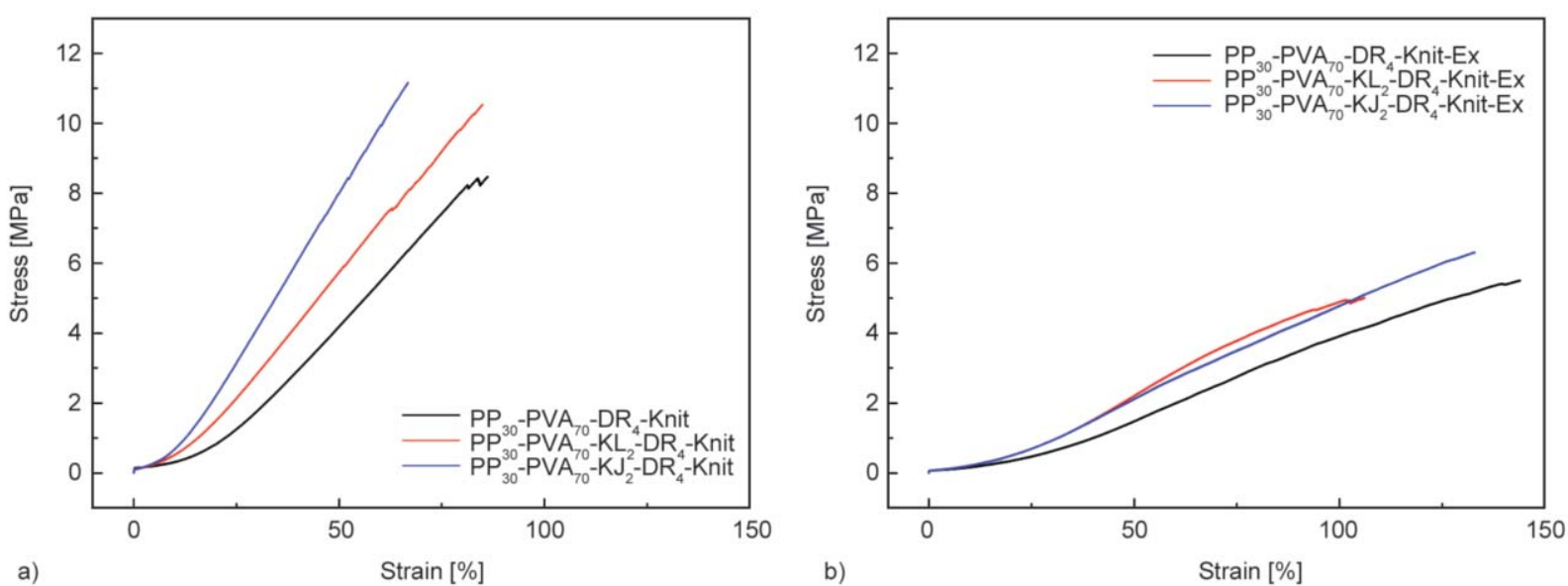

Figure 11. Stress-strain curves of knitted fabrics from $\mathrm{PP}_{30}-\mathrm{PVA}_{70}$ fibers (a) before selective phase extraction; (b) after selective phase extraction. 
phase extraction, the elongation at maximum force of the fabrics from $\mathrm{PP}_{30}-\mathrm{PVA}_{70}-\mathrm{DR}_{4}-\mathrm{Knit}$ is $86.3 \%$. The addition of $\mathrm{KL}$ and $\mathrm{KJ}$ particles significantly enhances the maximum stress from 8.6 to 10.8 and 11.3 MPa with an increment of 26 and $31 \%$, respectively. Meanwhile, the corresponding elongation is decreased with the incorporation of KJ particles. More detailed information lies in the stress-strain curves, and the enhancement effect of kaolinite particles is obviously distinguished from the sharp increment of the slope, especially with Janus particles. The stress concentration points control the breakage of the monofilament fibers, and the effect is relatively weakened in the form of the fabrics from multifilament yarns. It is ascribed that some monofilament fibers with less stress concentration points and better mechanical properties play an important role in the mechanical behaviors of the knitted fabrics.

The PP micro/nanofiber fabrics are manufactured after the selective phase extraction. For their mechanical behaviors, the new thickness is taken into account. It is found that the maximum stress is decreased, and the corresponding elongation is significantly increased, mainly due to the 'sliding effect' of obtained PP micro/nanofibers between loops. With the incorporation of unmodified kaolinite particles $\mathrm{KL}$, the maximum stress and corresponding elongation are decreased. Furthermore, KJ particles have no obvious impact on its corresponding elongation value and enhance the maximum stress from 5.8 to $6.8 \mathrm{MPa}$ with an increment of $17 \%$. The mechanical enhancement of the Janus kaolinite particles upon the fabrics still exists after PVA removal, attributed to the optimized aggregate structure of the PP phase. In conclusion, while imparting surface modification to the micro/nanofiber fabrics, the Janus kaolinite particles also endow them with better mechanical properties. In other aspects, the thicknesses of the fabrics, as well as their areal density, are decreased after the removal of PVA via selective phase extraction. Furthermore, the air permeability is slightly increased due to the loss of material. The most visible increment appears in the samples with Janus kaolinite particles after selective phase extraction.

\section{Conclusions}

In this paper, the ratio of PP and PVA blends is $30 \mathrm{wt} . \% / 70 \mathrm{wt} . \%$ for manufacturing the PP-PVA composite fibers, in which PP is transformed into micro/nanofibers in the PVA matrix phase. With the aid of green solvent water, the PP micro/nanofibers are obtained after the removal of the PVA phase. Kaolinite particles are incorporated into the $\mathrm{PP}_{30^{-}}$ $\mathrm{PVA}_{70}$ blends, of which raw kaolinite and Janus one particles are selected. TEM measurement confirms that Janus particles have a higher tendency to be confined at the interface. The multifilament yarns composed of the binary and ternary blends were successfully spun, and the knitting technology was adopted to create textile products followed by selective phase extraction. Numerous PP micro/nanofibers with diameters of hundreds of nanometers are released, and the knitting structure still maintains. The results demonstrate that some kaolinite particles are embedded with the PP phase, no matter which kaolinite particles are selected. The introduction of kaolinite particles may bring about more stress concentration points in the biphasic fibers; however, the enhancement effects still exist for the knitted fabrics with the Janus particles even after the selective phase extraction, with the optimized aggregate structure reflected in the increased crystallization degree. It sets an innovative example of manufacturing the thermoplastic polymer micro/nanofiber surface-modified and simultaneously mechanically enhanced with Janus particles.

\section{Acknowledgements}

The author Xiang Yan thanks for the financial support for $\mathrm{PhD}$ from China Scholarship Council.

\section{References}

[1] Fakirov S., Bhattacharyya D., Panamoottil S. M.: Converting of bulk polymers into nanosized materials with controlled nanomorphology. International Journal of Polymeric Materials and Polymeric Biomaterials, 63, 777-793 (2014). https://doi.org/10.1080/00914037.2014.886214

[2] Drabek J., Zatloukal M.: Meltblown technology for production of polymeric microfibers/nanofibers: A review. Physics of Fluids, 31, 091301/1-091301/26 (2019). https://doi.org/10.1063/1.5116336

[3] Jin K., Eyer S., Dean W., Kitto D., Bates F. S., Ellison C. J.: Bimodal nanofiber and microfiber nonwovens by melt-blowing immiscible ternary polymer blends. Industrial and Engineering Chemistry Research, 59, 5238-5246 (2019). https://doi.org/10.1021/acs.iecr.9b04887

[4] Raghavan B., Soto H., Lozano K.: Fabrication of melt spun polypropylene nanofibers by forcespinning. Journal of Engineered Fibers and Fabrics, 8, 52-60 (2013). https://doi.org/10.1177/155892501300800106 
[5] Acik G., Altinkok C.: Polypropylene microfibers via solution electrospinning under ambient conditions. Journal of Applied Polymer Science, 136, 48199/148199/6 (2019).

https://doi.org/10.1002/app.48199

[6] Fedorova N., Pourdeyhimi B.: High strength nylon micro- and nanofiber based nonwovens via spunbonding. Journal of Applied Polymer Science, 104, 3434 3442 (2007).

https://doi.org/10.1002/app.25939

[7] Ayad E., Cayla A., Rault F., Gonthier A., Campagne C., Devaux E.: Effect of viscosity ratio of two immiscible polymers on morphology in bicomponent melt spinning fibers. Advances in Polymer Technology, 37, 11341141 (2018).

https://doi.org/10.1002/adv.21772

[8] Karthik T., Rathinamoorthy R.: Nonwovens: Process, structure, properties and applications. WPI, New Delhi (2017).

[9] Fakirov S.: Nano-/microfibrillar polymer-polymer and single polymer composites: The converting instead of adding concept. Composites Science and Technology, 89, 211-225 (2013).

https://doi.org/10.1016/j.compscitech.2013.10.007

[10] Fakirov S.: Nanofibrillar polymer-polymer and single polymer composites via the 'converting instead of adding' concept - Examples of true polymer nanocomposite. Advanced Industrial and Engineering Polymer Research, 1, 40-47 (2018).

https://doi.org/10.1016/j.aiepr.2018.02.001

[11] Wang D., Sun G.: Formation and morphology of cellulose acetate butyrate $(\mathrm{CAB}) /$ polyolefin and $\mathrm{CAB} /$ polyester in situ microfibrillar and lamellar hybrid blends. European Polymer Journal, 43, 3587-3596 (2007). https://doi.org/10.1016/j.eurpolymj.2007.05.018

[12] Robeson L. M., Axelrod R. J., Vratsanos M. S., Kittek M. R.: Microfiber formation: Immiscible polymer blends involving thermoplastic poly(vinyl alcohol) as an extractable matrix. Journal of Applied Polymer Science, 52, 1837-1846 (1994).

https://doi.org/10.1002/app.1994.070521301

[13] Wu T., Yuan D., Qiu F., Chen R-Y., Zhang G-Z., Qu J-P.: Polypropylene/polystyrene/clay blends prepared by an innovative eccentric rotor extruder based on continuous elongational flow: Analysis of morphology, rheology property, and crystallization behavior. Polymer Testing, 63, 73-83 (2017).

https://doi.org/10.1016/j.polymertesting.2017.07.012

[14] Dedzo G. K., Detellier C.: Functional nanohybrid materials derived from kaolinite. Applied Clay Science, 130, 33-39 (2016). https://doi.org/10.1016/j.clay.2016.01.010

[15] Su L., Zeng X., He H., Tao Q., Komarneni S.: Preparation of functionalized kaolinite/epoxy resin nanocomposites with enhanced thermal properties. Applied Clay Science, 148, 103-108 (2017). https://doi.org/10.1016/j.clay.2017.08.017
[16] Hirsemann D., Shylesh S., De Souza R. A., Diar-Bakerly B., Biersack B., Mueller D. N., Martin M., Schobert R., Breu J.: Large-scale, low-cost fabrication of Janus-type emulsifiers by selective decoration of natural kaolinite platelets. Angewandte Chemie International Edition, 51, 1348-1352 (2012).

https://doi.org/10.1002/anie.201106710

[17] Batistella M., Otazaghine B., Sonnier R., Petter C., Lopez-Cuesta J-M.: Fire retardancy of polypropylene/ kaolinite composites. Polymer Degradation and Stability, 129, 260-267 (2016).

https://doi.org/10.1016/j.polymdegradstab.2016.05.003

[18] Daitx T. S., Jacoby C. G., Ferreira C. I., Schneider P. H., Mauler R. S.: Kaolinite-based Janus nanoparticles as a compatibilizing agent in polymer blends. Applied Clay Science, 182, 105291/1-105291/8 (2019). https://doi.org/10.1016/j.clay.2019.105291

[19] Weiss S., Hirsemann D., Biersack B., Ziadeh M., Müller A. H., Breu J.: Hybrid Janus particles based on polymermodified kaolinite. Polymer, 54, 1388-1396 (2013). https://doi.org/10.1016/j.polymer.2012.12.041

[20] Yan X., Cayla A., Devaux E., Otazaghine B., Salaün F.: Polypropylene/poly(vinyl alcohol) blends compatibilized with kaolinite Janus hybrid particles and their transformation into fibers. Industrial and Engineering Chemistry Research, 58, 10931-10940 (2019). https://doi.org/10.1021/acs.iecr.9b01990

[21] Yan X., Cayla A., Salaün F., Devaux E., Liu P., Mao J., Huang T.: Porous fibers surface decorated with nanofillers: From melt-spun PP/PVA blend fibers with silica nanoparticles. Journal of Applied Polymer Science, 137, 48470/1-48470/11 (2020). https://doi.org/10.1002/app.48470

[22] Yan X., Cayla A., Salaün F., Devaux E., Liu P., Huang T.: A green method to fabricate porous polypropylene fibers: Development toward textile products and mechanical evaluation. Textile Research Journal, 90, 547560 (2020). https://doi.org/10.1177/0040517519871944

[23] Yah W. O., Takahara A., Lvov Y. M.: Selective modification of halloysite lumen with octadecylphosphonic acid: New inorganic tubular micelle. Journal of the American Chemical Society, 134, 1853-1859 (2012). https://doi.org/10.1021/ja210258y

[24] Yan X., Cayla A., Devaux E., Salaün F.: Microstructure evolution of immiscible PP-PVA blends tuned by polymer ratio and silica nanoparticles. Polymers, 10, 1031/11031/17 (2018). https://doi.org/10.3390/polym10091031

[25] Soyaslan D., Çömlekçi S., Göktepe Ö.: Determination of electromagnetic shielding performance of plain knitting and $1 \times 1$ rib structures with coaxial test fixture relating to ASTM D4935. Journal of the Textile Institute, 101, 890-897 (2010). https://doi.org/10.1080/00405000902945360

[26] ASTM D 1238-10: Standard test method for melt flow rates of thermoplastics by extrusion plastometer (2010). 
[27] Brandrup J., Immergut E. H.: Polymer handbook. Wiley, New York (1989).

[28] EN ISO 5079: Textile fibres - Determination of breaking force and elongation at break of individual fibres (1996).

[29] Devaux E., Aubry C., Campagne C., Rochery M.: PLA/ carbon nanotubes multifilament yarns for relative humidity textile sensor. Journal of Engineered Fibers and Fabrics, 6, 13-24 (2011).

https://doi.org/10.1177/155892501100600302

[30] ASTM D 1777-96: Standard test method for thickness of textile materials (2007).

[31] EN ISO 9237: Textiles-determination of the permeability of fabrics to air (1995).
[32] Ku T-H., Lin C-A.: Rheological properties of thermoplastic polyvinyl alcohol and polypropylene blend melts in capillary extrusions. Journal of Polymer Research, 12, 23-29 (2005). https://doi.org/10.1007/s10965-004-0985-9

[33] Dabrowska I., Fambri L., Batistella M., Lopez-Cuesta J. M.: Compounding and spinning of polypropylene nanocomposites with kaolinite. in 'Proceeding of ECCM16-16 ${ }^{\text {th }}$ European conference on composite materials. Seville, Spain', 109290/1-109290/26 (2014).

[34] Cho D., Zhou H., Cho Y., Audus D., Joo Y. L.: Structural properties and superhydrophobicity of electrospun polypropylene fibers from solution and melt. Polymer, 51, 6005-6012 (2010).

https://doi.org/10.1016/j.polymer.2010.10.028 